\title{
Lapurdum
}

LAPURDUM Euskal ikerketen aldizkaria | Revue d'études basques |

Revista de estudios vascos | Basque studies review

$6 \mid 2001$

Numéro VI

\section{Nz-bait izenordain zehaztugabeen jatorriaz}

\section{Ricardo Etxepare}

\section{OpenEdition \\ Journals}

Édition électronique

URL : http://journals.openedition.org/lapurdum/1193

DOI : 10.4000/lapurdum. 1193

ISSN : 1965-0655

Éditeur

IKER

Édition imprimée

Date de publication : 1 octobre 2001

Pagination : 93-117

ISBN : 2-84127-156-0

ISSN : $1273-3830$

\section{Référence électronique}

Ricardo Etxepare, « Nz-bait izenordain zehaztugabeen jatorriaz », Lapurdum [Linean], 6 | 2001, Sarean emana---an 01 juin 2009, kontsultatu 01 février 2020. URL : http://journals.openedition.org/lapurdum/ 1193 ; DOI : 10.4000/lapurdum.1193 


\section{NZ-BAIT IZENORDAIN ZEHAZTUGABEEN JATORRIAZ}

\section{Sarrera ${ }^{1}$}

Izenordain zehaztugabeen eremuak euskaraz nor/zer galderazkoak ${ }^{2}$ eta haien gainean eraikitako zenbatzaileak biltzen ditu (EGLU I, 87-103; EGLPB, 58-67): norbait/zerbait gisako existentzialak, edonor, zernahi bezalako unibertsalak eta inor/ezer polaritatedunak ${ }^{3}$. Eremu hau, orohar, bereziki egongaitza eta aldakorra da diakroniaren aldetik (ikus, gainbegiratu orokor baterako, Haspelmath, 1997, seigarren kapitulua). Lan honek euskarazko nor/zer-bait-en gisako izenordain zehaztugabe existentzialen jatorria tratatzen $\mathrm{du}$, eta hipotesi berri bat defendatzen: nor/zer+bait formak adjunktu funtzioa betetzen duten perpaus erlatibo libreetarik heldu direla. Hipotesi honen arabera, forma horien azpian honelako egiturak izango genituzke ${ }^{4}$ :
a. ... bainan zuek trublatzen zaituztenak, ekarriren du kondemnazioa, nor ere baita hura (Leizarraga, Gal 5, 10)
b. ...bainan zuek altaratzen zaituztenak ekarriko du horren pena, nor ere baida hura (Hnd. Ibidem)

Biak latinezko "qui autem conturbat vos, portabit iudicium, quicumque est ille"-ren itzulpenak.

Batetik besterako bidea (hau da, balio unibertsaleko perpasu erlatibo libreetarik balio existentzialeko izenordain mugagabeetarainokoa) tipologian ondo bermatua dago (ikus 3.atala), eta hipotesiak euskaraz izenordain zehaztugabe existentzialek erakusten duten forma aldeko ugaritasuna zehazki mugatzeko bidea ematen du. Garrantzi haundia izango dute, hipotesi honen justifikazioan, izenordain zehaztugabe existentzialen jatorriaz arduratu diren ikerlari bakanek (Lafon, 1944, 1966 eta 1973; Trask, 1997) aintzat hartu ez dituzten eta itxura batean osoagoak ematen duten forma historiko batzuk, hala nola norbaita, zerbaita edo noizbaita bezalakoak.

\section{1. $\quad N z . .$. -bait formak ahozko eta idatzizko tradizioan}

Gauza jakina da norbait/zerbait gisako formen esparruak aldaera ugari dauzkala ahozko nahiz idatzizko tradizioan. Atal honetan, aurkitu ahal izan ditudan aldaera guztiak bildu ditut. Aldaera guztiok lau egitura orokorretan bil daitezke. Egitura hauek atalburuan ematen ditut.

\section{1. [[NZ [ (PL) [KASUA/POSPOSIZIOA]]] [ BAIT]] formak}

Honelakoetan aipatuenak (Lafon, 1966) Dechepare-k dakarzki:

(2) a. Norc baytere amoria niri daraut muthatu (VII,7)

b. Norc vaytere eguyn deraut malicia handia (XIII, 31)

Horiez gain, Añibarrok noribait ere dakar ( $\mathrm{EL}^{2}$ 137). Nortzu formekin lotuak dira XIX.mendean Bizkaiko autoreengan agertzen diren nortzukbait (Astarloa II, 194 eta Uriarte MarIl, 60) eta Juan Jose Mogelen nortzuibait, hemen ematen duguna': 
(3) Egija da emen [...] ez dakigula iñok bere ziur ziur grazijaan aurkituten garianik, Jangoikuak nortzuibait agertu edo errebelatu ez badautsee (Mayatz 51)

Gipuzkoan, Agirre Asteasukoaren etsenpluak ere baditugu:

(4) Nai nuke nork ere bait begi onez ekustea, gizonai ederra iritsitzea (Eracusaldiac, III, 552)

Kasua tartean agertzen duten etsenpluez gainera, badira ere pospozizioa tartean agertzen dutenak. Horietako batzuk egun ere ohikoak dira (nonbait, noizbait, nolabait eta norabait), baina ez guztiak: Azkuek zertazbait (R-bid) "de algo, de quelque chose") eta zetanbait (B-mañ) "por algo, en busca de algo; pour quelque chose, en quête de quelque chose". Horiekin batera nondikbait eta nondik-baitetik ere badugu (OEHtik):

(5) a. Lar-abere asko zan orduan erori/Alere sortu dira nondik bait iori (Izt, Condaira, 195)

b. Nondikpaitik aditu dut “j' ai entendu de quelque part” (Dv, Hiztegia)

\section{2. [[NZ [(B)ERE [BAIT]]]}

Nola-rekin, baditugu nolarebait, nolerebait (Azkuek Gipuzkoan bilduak) eta nola(b)erebait eta nulerebait (Azkueren arabera zubereratikoak). Non-ekin: nunerebait, nonberebait "seguru aski" esan nahi dutenak (Añibarrorengan) eta nunerebait "nonbait (lekuzkoa)" (Beovide, AsL 205). Mendiburuk noraerebait dakar eta Urte-k (Hiztegia I, 501), Agirre Asteasukoak eta Beovide-k noizerebait. Horra exenplu gisa (6):

(6) Noiz-ere bait biur gaitezen gerengana, nere kristauak (Eracusaldiac, III, 343)

Forma hauen sailean sartzen dira baita ere Leizarragaren cembaterebeit, cembatrebeit, eta ceimbaitrabeit:

(7) a. Eta egon guentecen hiri hartan cembatrebeit egun (Apostoluen Acteac 16,12)

b. Igorrac cembaiterebeit gende Ioppera... (Apostoluen Acteac 11, 13)

c. Eta cembaitrabeit egunean buruan,... (Apostoluen Acteac 24, 24)

\section{3. [[NZ [-KO [-A]]] BAIT]]]}

Azkuek nolakoabait (AN, BN, G, L...) ematen du hiztegian "regulier, passable, de qualité quelconque" esanahiarekin. Baita zelangoabait ere (bait- sarreran, esangura adierazi gabe).

\section{4. [NZ [(ERE) [BAITA]]]}

Bere morfologian (266. Sarrera, 192.orr.), eta hiztegian ere bai, ohiko norbait/zerbait, norbeit/zerbeit eta norbaist/zerbaist-en ondoan, Azkuek nopaita (B) eta zepaita (B-mu) ere jasotzen ditu. Nopaitxe aldaera ere jasoa dago (OEH: Ortuzar, 
Voc, 141, V-ger), eta gaur egun bizirik dirau gutxienez Bermeon, zepaitxe -rekin batera (Bilbao, 1998). Bermeoko euskaraz idatzitako De la Quadraren 1784ko dotrinan (Bilbao, 1998) norbaita aurkitzen da:

(8) iñoc norbaita ilten dabenian... (Doctr.54)

Zerbaita forma, bere aldetik, ez da guziz arrotza testuetan: Juan de Zumarragaren gutunean agertzen da (A Tovar, E. Otte \& L. Michelena, 1981; Sarasola, 1983):

(9) mjlla ducat bidalduco ditugula urte onetan njc uste: orayn vere cerbayta voa,...

Juan Ortiz de Velascoren itzulpenean cerbayta hori egungo zerbait arrunta $\mathrm{da}^{6}$ : "... pienso que enbiaremos este mill ducados. Tanbien ba algo agora..."

Norbaita/nopaita eta zerbaita/zepaita formez gainera, nunbaita eta nospaita ere aurkitzen dira ${ }^{7}$. Añibarro-k nunbaite dakar Esku Liburuan. Nunbaita Urquizuren bertsoetan (1737) agertzen da (OEHaren nonbait 2 sarreratik) "seguru aski" ren esanahiarekin:

(10) orra nun doian erruki baga/odolezko iturriia/nunbaita oorain amaituko al dau/bere betiko egarriia

Azkuek, Euskalerriaren Yakintzan nunbaita be (B-1) eta nunbaite be (B, Alt) jasotzen ditu "jakina, noski, bai horixe"-ren esanahiarekin, eta hiztegian berriz nunebeita (S) "noski, seguru aski"ren adierarekin baita ere, mende honetan Eskualduna aldizkaritik hartua ${ }^{8}$ :

(11) Berantto orai mahatsez mintzatzeko, erranen dü nunebeita irakurzale batek beno haborok (Eskualduna, 17-XI-1905)

Noizbaita-ri dagozkion aldaerak ere badira: Olaetxearen dotrinan (1740) eta Zuzaetaren idazkietan (XVIII. mendearen bukaeran). Olaetxearen exenplua, hauxe (OEH, noizbait sarrera, 847.orr.):

(12) Nos baita bearra egin lei domeka eta jaiegun bearrik ez egiteko esanta dagozanetan?

Eta Zuzaetarena:

(13) Azkenik dauko obligaziñoia nosbaita emaztiaren konsejuba artu eta bere esana egiteko

2. Egungo izenordain zehaztugabe existentzialen sorreraz bi hipotesi: Lafon $(1944,1966,1978)$ eta Trask (1997)

Azkue izan zen lehenbizikoa ohartzen (edo ohartarazten) norbait/zerbait formetako -bait atzizkia menpekotasuna markatzeko baliatzen den bait- flexioaurrizki berbera izan zitekeela (Morfologia Vasca, I, 529. sarrera). Azkuerentzat, 
deigarri egiten zen izenordainei lotzen zaien atzizki horrek aldaera dialektal bat duenean, adizki jokatuari lotzen zaion aurrizkiak ere aldaera bera izatea. Honela, baist (Azkuek B, hau da bizkaikoa) eta -beit (Azkueren arabera S, hau da Zubererari dagokiona) - bait orokorragoaren aldaerak baldin badira, adizki jokatuari lotzen zaien aurrizkien kasuan eremu bertsuetan aldaera berberak aurkitzen ditugu?

Lafon-ek Azkueren ohartarazpena aintzakotzat hartu eta urrutiago eramanaz aurrizki-atzizkien identitatearen tesia proposatu zuen (1944, 481-491.orr.; 1966; 1973, 43-45.orr.). Lafon-en arabera, bait funtsean baiezkotasuna azpimarkatzeko erabiltzen den bai forma librearen kidea $\mathrm{da}^{10}$. Bait forma, adizki jokatuari nahiz izenordainkiari lotzen ahal zitzaien. Ikuspegi honetan, nor baitago eta norbait dago biak ere *nor bait dago zaharrago batetik heldu dira, zeinetan bait formak alde batera edo bestera egin zezakeen, baiezko tasuna izenordainkiari edo adizki jokatuari (eta beraz, proposizioari) eratxekiaz. Bait, egun, izenordainkiaren edo forma jokatuaren parte da, baina haren behinolako izaera librea izenordain zehaztugabeen aintzineko zenbait formatan ere igar daiteke. Honela, esate baterako, Dechepare-k nork bait ere dakar, ohikoa dugun norbaitek-en aldean (ikus 1.1. atala). Asumituaz flexioari (eta beraz, kasuari) dagozkion morfemak sintagma "itxi" egiten dutela zernahi ondoko operazio morfologikorentzako, Dechepare-ren forma horiek bait oraindik bere eskuko zen garaia jasotzen dute, Lafonen iritzian ${ }^{11}$.

Trask-ek (1997, 197-198.orr.) Lafon-ek ez bezala, bait forma jatorrian adizki jokatuari dagokiola proposatzen du. Harentzat, nor/zer formak galderazkoak nahiz mugagabe hutsak izan zitezkeen, baina mugagabeko formek bait- aurrizkia galdetzen zuten beti adizki jokatuan. Delako egoera hartan, *nor baitzen bezalako hurrenkerak bestelako zatiketa baten bidetik interpretatzen hasi ziren: norbait zen gisa, alegia. Hortik egungo mugagabeak $^{12}$.

Bai Lafon-ek eta bai Trask-ek gogoan duten ustezko aurreko egoeran, euskarazko nor eta zer bezalako galdera hitzek berezko balio zehaztugabea dute, eta beregainki jokatzen dute sintaxian. Hau propietate tipologiko arrunta da, munduko hizkuntza askok erakusten dutena (ikus, besteak beste, Cheng,1991;Bhat,2000).

Lafonen eta Trask-en hipotesiak ez dira hein berean moldatzen bildutako mugagabeen aldaeren aurrean. Har esate baterako 1.1. ataleko kasuak, kasu marka nor/zer-en eta bait partikularen artean agertzen direnekoak:

Nork baitere amoria daraut muthatu

Lafonentzat, Dechepareren etsenplu honek bait partikula bere eskuko zen garai bat ematen digu aditzera. Egungo termino sintaktikoak erabiliaz, esan genezake bait, baiezkotasuna adierazten duen bai-rekin lotua dena, maila proposizionaleko buru funtzional bat dela, edo gisa horretako buru bati lotua dela (Laka,1990 -en zentzuan). Nork horrenbestez, buru hori baino gorago dago. Lakari jarraituaz buru hori Sigma izendatuko dugu:

$$
\text { [SSint } \operatorname{Nork}_{\mathrm{i}} \text { [sSint baitere [IP } \mathrm{t}_{\mathrm{i}} \text { amoria daraut muthatu]]] }
$$


(15)eko egitura guziz hipotetikoa da noski, baina maila proposizionaleko morfemek haien semantikarekin zer ikusia duen posizio sintaktiko bat hartzen badute, (15) ezin da urrutiegi ibili behintzat nork eta bait-en elkarrekiko kokapenari dagokionean. Trask-en hipotesian, ordea, hasiera batean adizki jokatuari lotua den aurrizkiak izenordainarekin bat egiten bukatu behar luke. Bat egite hori bide morfologiko ohikotik egiten baldin bada, handik sortzen den forma konplexuak ezin du kasu marka bere baitan hartu. Nolabait esateko, Decheparerena bezalako kasuetan bait- aurrizkia bide erdian gelditu da: adizki jokatutik urrutiegi eta izenordainarengana txit ailegatu gabe.

Bata zein bestearen hipotesiak, bestalde, zer esanik ez dute 1.4.-ko (nopaita/zepaita) formei buruz.

\section{Euskarazko izenordain zehaztugabeak tipologiaren argitan}

Haspelmath (1997)-ek, gaur arte gai honen inguruan egin den lanik zabal eta osoenean, izenordain zehaztugabeak kasurik gehienetan deribaturiko formak direla defendatzen $\mathrm{du}$, galderazko izenordainen edo izen mugagabe sinple baten eta indar kuantifikazionala eratxekitzen dion partikula baten elkarketaz eratuak. Euskararen izenordain zehaztugabeen sailari begiratzen badiogu, jeneralizazioa ezin zuzenagoa da:

$$
\begin{array}{cccc}
\text { Esistentzialak } & \text { Polaritatedunak } & \text { Unibertsalak-1 } & \text { Unibertsalak-2 } \\
\text { Nor- bait } & i \text {-nor } / \text { ne } \text {-hor } & \text { nor-nahi } & \text { edo-nor } \\
& (<* \text { e-nor, Mitxelena, 1985) } &
\end{array}
$$

Tipologiaren aldetik, izenordain sinpleei ezartzen zaizkien partikula edo emendailu horiek bi iturburu nagusi dute: lehena, zehazkabetasuna adierazten duten perpaus osoen gramatikalizazioa da; bigarrena, galderazko izenordainaren edo izen mugagabe sinplearen denotazio egituran mailakatze bat eragiten duten foko partikulak dira $^{13}$. Bi iturburu hauen adibide gisa, hona hemen bi kasu, lehena Lituanierari dagokiona, bigarrena Serbo-kroazierarena (Haspelmath, 1997, 131 eta 138.orr.) ${ }^{14}$.

$$
\begin{aligned}
& \text { a. kaz-kas (kazin-kas, kazno-kas) "norbait" < kas zino kas "nork daki nor" } \\
& \text { b. i-ko "edonor" < i- "ere" + -ko "nor" }
\end{aligned}
$$

Lituanieraren kasuan, gramatikalizaturiko perpaus nagusi oso bat haren menpekoa zen (edo haren menpekoaren barnean) zen galdera hitzaren aurrizki bilakatu da. Bigarren kasuan, euskarazko ere-ren kide den zerbait galdera hitzari zuzenean lotzen zaio izenordain zehaztugabe unibertsal bat eratzeko.

$\mathrm{Bi}$ prozedura hauek predikzio desberdinak egiten dituzte euskarazko izenordain zehaztugabe existentzialen izaerari eta jatorriari buruz. Lehen bideari segituez gero, nor/zerbait sailaren azpian gramatikalizaturiko perpaus osoak ditugu. Bigarren bideari jarraituez gero, -bait jatorrian behintzat mailakatze balioa zuen foko partikula bat da, nor/zer galderazkoei lotzen zitzaiena.

Horrekin lotua dago bigarren problema bat: Azkuek eta Lafonek bait aurrizkiatzizkien artean ikusi uste izan zuten kidetasuna zinezkoa bada, zer egiten dugun itxuraz osoagoa den -baita atzizkiarekin. Azkue-Lafon-en bidetik abiatuta, bi aukera 
daude bakarrik: edo bait- aurrizkia jatorrian baita- da eta adizki jokatuen aurrean (eta euskalki gehienetan, hitz bukaeran) bokala galdu du, edo -baita atzizkiak badu erantsizko zerbait, oraindik identifikatu ez duguna, eta oinarrizko forma adizki jokatuekin aurkitzen duguna da.

Lehen problema sailari gagozkiola, bigarren hipotesia besterik gabe bazter daitekeena da. Nor/zer galderazkoaren ondoan datorrena ez da mailakatze funtzioa duen foko partikula bat, baizik eta konplementatzaile bat, proposizio mailako menpekotasun erlazio bat adierazten duen zerbait, Azkuek eta Lafon-ek ikusi zuten bezala $^{15}$. Honenbestez argi dago izenordain zehaztugabeen jatorriari begiratuez gero, lehen hipotesiari jarraiki behar gatzaizkiola, eta ez bigarrenari. Honek, edozein kasutan ere, ez digu bigarren arazoa konpontzen, alegia konplementatzailearen eta izenordain zehaztugabeak sortzen dituen atzizkiaren azpian baita dagoen, ala -baita atzizkia eta bait- aurrizkia bereizi behar ditugun. Ohar gaitezen gramatikalizazioaren bidetik jotzen badugu, bukaerako $-a$ hori gramatikalizazio prozesuan karriaturiko elementu bat izan daitekeela, jatorrian bait atzizkitik berezia dena. 3.1. atalean lehen posibilitatea tratatuko dut laburki. 3.2. atalean, bigarrena eta hobetsiko dudana.

\subsection{Litekeen baita- aurrizkiaz}

Bait- aurrizkiaren eta -bait atzizkiaren azpiko forma baita bada, ez da beharbada burugabea biak balizko bai eta batetik heldu direla pentsatzea ${ }^{16}$. Adizki jokatuei lotzen zaien aurrizkiari dagokionean, ez dirudi fonologikoki problema haundiak sortzen dituenik: baita, baitu forma jokatuen azpian honelako prozesu bat izango genukeen:

$$
\begin{aligned}
& \text { *bai eta da }>* \text { baita da }>* \text { baitaa }>\text { baita } \\
& \text { *bai eta dadu }>\text { baita dadu }>\text { baitadau }>* \text { baitau }>\text { baitu }
\end{aligned}
$$

Bait- forma laburragoa bilakaeraren emaitzak ahalbideraturiko segmentazio berri baten ondorio izango litzateke.

Azpiko eta ren presentziak esplika lezake zergatik bait -ek berez denborazko balioa izan dezakeen Lafon-ek aspaldi nabarmendu egitura batzuetan (Lafon, 1966, 683-686; Oihartzabal, 1987):

(19) zu jin báit, eginik duket "pour votre arrivée, je l'aurai fait" (Lafon,1966, 683.orr.)

Bait- beste aldetik, bitxia da menpekotasun erlazio oso desberdinak markatzen dituelako (kausalak, moduzkoak, denborazkoak, Lafon, 1966; Oihartzabal, 1987). Jakina da juntagailuak subordinazioari dagozkion menpekotasun erlazioak ahalbideratzen dituztela, behin diskurtsuan txertatuez gero (Culicover eta Jackendoff, 1997; edo Rebuschi, 2001, juntaketa eta subordinazioaren arteko mugak desegiten dituen ikuspegi baterako), eta menpekotasun erlazio hauek askotarikoak izan daitezkeela. Bait- en azpian bai eta- dagoen ala ez berariazko azterketa merezi duen kontua da, nere irudiz, baina ez dut uste izenordain zehaztugabe esistentzialen jatorria argitzeko orduan argi gehiegi egiten digunik. Batetik, ez dugu batere lekukotasunik konplementatzaile gisa funtzionatzen duen bait- aurrizkiari dagokion azpiko forma baita dela erakusten duenik. Pentsatzekoa da hala ere, delako -baita atzizkia, bere 
osotasunean mantendu bada izenordainen sailean, arrastoren bat utziko zuela baita ere adizki jokatuen dermioan. Baina ez dugu bakar bat ere.

\subsection{Gramatikalizazioaren hipotesia}

Bildu ditugun aldaera guziak elkarrekin jartzen baditugu eta haien elementuak forma bakar batean biltzen, ateratzen den emaitza ezagun egiten zaiguna da. Nor/zer absolutibo batetik abiatuez gero, honakoa:

(20) Nor/zer...(forma guziek dutena) $=>$

Nor/zer ere... (1.2. formetatik) $=>$

Nor/zer ere bait... $(1.1,1.2,1.3)=>$

Nor/zer ere baita (1.4. ko formek erakusten duten akabuko bokala erantsiaz)

Baina, noski, azken forma hau erlatibozko libre bat da, nor/zer galderazkoen gainean eratutakoa. Hona, esate baterako, kasu eta preposizio desberdinak agertzen dituzten izenordain zehaztugabeei (1.1. formak) dagozkien (edo legozkiekeen) ale batzuk ${ }^{17}$ :

(21) a. Nor ere baita ez da sarthuko "Quel qu'il soit, il n'entrera pas" (Duvoisinen hiztegitik) ${ }^{18}$

b. Nola ere baita, bada fikzionez, bada egiaz, Krist predikatzen da "en quelque manière que ce soit" (Leiç., Phil 1)

c. Non ere baita "quelque part qu'il soit" (Pouvreau, Hiztegia)

Tipologikoki, egitura hauek oso iturburu ohikoa dira izenordain zehaztugabeentzat. Haspelmath-en arabera (1997, 129-139.orr.), gramatikalizazioz eratu diren izenordainek hiru iturburu nagusi dituzte: lehen iturburua, berak ez dakit zer gisako zehaztugabeak (ingelesez dunno type) deitzen dituenak sortzen dituena $\mathrm{da}^{19}$. Honelakoetan perpaus nagusi oso bat zehazkabetasuna adierazten duen aurrizki bilakatzen da. Perpaus hori jakingabetasuna adierazten duena izaten da. Horrelakoak aurkitzen dira esate baterako Ingeles Zaharrean (22a), Bitarteko Goi Alemanieran (Middle High German, (22b)), eta egungo errumanieraz, dialektalak diren formetan (22c) (Haspelmath, 1997, 131.orr.):
a. nathwa "norbait" <ne wat hwa "ez dakit nor(k)"
b. neizwer "norbait" <ne weiz wer "ez dakit nor(k)"
c. nestine "zenbait" < Latinezko nescio quis "ez dakit nor(k)"

Bigarren iturburua, nahi/gogo-ren presentzia erakusten duten izenordain zehaztugabeak sortzen dituena da (want/please type): nor/zer bezalako izenordainkiei lotuak agertzen diren hainbat atzizki nahia, gogoa edo atsegina adierazten duten elementuak dira, normalki aditz lexikalizatuak (Haspelmath, 1997, 132. orr.). Hauek erlatibo libreetarik heldu dira. Kasu ezagunak dira gure artean latinezkoak (23a), eta espainolezkoak (23b). (23c) errumanierako forma dialektal bat da:

(23) a. qui-vis edo quilibet "inor" <qui "nor" + vis "nahi duzun" edo libet "atsegin den"

b. cualquiera "edozein, zernahi" <cual "zein" + quiera "nahi duen"

c. cine-va "norbait" (cine "zein" + va<vrea "nahi du") 
Euskarazko zernahi-k, dakigunez, iturburu bera $\mathrm{du}^{20}$.

Azkenik, Haspelmath-ek "it may be" type indefinites deitzen duenen saila dago. Hauek predikazio kopular baten gainean eraikitako erlatibo libreetarik heldu dira. Erlatibo libre hauek euskarazko nor/zer/zein ere baita formen kide garbiak dira. Adibidetzat, frantsesezko (24a), errusierazko (24b) eta hebraierazko (24c):

a. Qui que ce soit "zein ere baita"

b. kto nibud "inor, norbait" <kto ni budi (kto "nor", ni "ere" budi "baita")

c. $m i-s e-h u$ "norbait" < "nor ere baita"

Euskarazko nor/zerbait formak beraz, sail honi legozkioke: azpian predikazio kopular bat duten erlatibo libreetarik eratorritako izenordain zehaztugabeen sailari alegia. Aipatzekoa da (zernahi-ren gramatikalizazio patroi bertsuari jarraikitzen zaiolarik), forma hauetan zehazkabetasuna adierazten duen partea atzizkia dela, espero litekeen bezala. Honek (ikus azken atala) zernahi eta zerbait sailak edonor eta inor sailetatik bereizten ditu. Lehenbizikoen kasuan, gramatikalizazio prozesuak, erlatibo libreetarik abiatuaz, atzizkiak sortu ditu, erlatibo libreetan nor/zer izenordainkiak erlatibatzearen markaren edo aditz-izenaren (zernahi-ren kasuan) aurretik doazelako ${ }^{21}$. Edonor eta inor-en sailak, aurrizkien bitartez eratuak, litekeena da gramatikalizazio prozesu baten emaitza ez izatea, baizik eta izenordainkien gainean zuzenean eraikitako formak $^{22}$.

Gramatikalizazio prozesuaren azpian dauden erlatibo forma hauek berehala esplikatzen dute aurreko hipotesietan zail gertatzen ziren aldaera batzuk. Batetik, norbaita/zerbaita bezalakoak, erlatibo librearen adizki jokatua osorik gordetzen duten formak dira. Nolakoabeit bezalakoak, beste alde, nolakoa baita erlatibo libreari dagozkio. Horrelakoak ere arruntak dira tradizio literarioan ${ }^{23}$ :

(25) a. Zelangoa baista amea, alangoa oi da alabea (RS, 35)

b. Nolako baita nihor bera baitan, hala iujeatzen du kanpotik (SP Imit II 4, 2)

Kasua tartean agertzen duten egiturak, -bait(a) formek oraindik erlatibozko librearen barne egitura gordetzen duten egoera jasotzen dute. Nolerebait bezalako formak mailakatze partikula (ere) gorde duten erlatibo libreetarik eratorritako forma fosilizatuak dira.

Esan behar da, kasu marka tartean agertzen duten etsenpluetan, kasua perpaus nagusiko flexioak ezartzen duela. Kasu marka galdera izenordainari atxikia erakusten duten izenordain guztiak behinolako perpaus oso baten egitura morfologikoa besterik gordetzen ez duten forma lexikalizatuak dira. Begiak antzeko gramatikalizazio prozesua jasan duten nornahi/zernahi formetara itzultzen baditugu, iduri du kasu menpekotasun hau, adizki jokatua bera galdu baino lehenagokoa izan zitekeela (OEH, nornahi sarrera, nork nahi den azpi sarrera):

(26) a. Fideletaric nork nahi den Iainkoa bere aita dei ahal dezake partikularki (Leiç.,Ins E 4v)

b. ...nork ere nahi den egin lezan (Samper)

\subsection{Bokalaren erorikoaz}


Hau guztia zuzena baldin bada, egungo formak norbaita/zerbaita formetarik sortuak dira, bukaerako bokala erori ondoren. Bokalaren eroriko hau ondo ordezkatua dago adizki jokatuen bukaerako $-a$ ren kasuan (ikus Mitxelena, FHV, 131-132; De Rijk, 1981).

Hori horrela bada, baina, predikzio garbi bat egiten dugu: espero dugu gramatikalizazio prozesuan bitarteko egoera bat aurkitzea, zeinetan bokala hitzaren azken posizioan gertatzen ez denean, forma osoena aurkitzen baitugu. Bizkaialdeko idazleengan (gogora nopaita/zepaita formak bizkaieraz aurkitzen direla bakarrik) aurkitzen ditugun alternantzia bitxi batzuk bitarteko egoera horren adierazle izan litezke. Ez Juan Antonio Moguelek, ez Zavalak, ez eta Vicenta Moguel-ek ere ez dute zerbaita bezalako formarik agertzen, baina bai, itxura batean, haietatik eratorritako zerbaitako forma:

(27) a. Bizi naizala banaiz zerbaitako; illtzen banazute, ez ezertako (V.Moguel, Ipui Onak, 96)

b. Bizi nazala banaz zerbaitako; ilten banozue ez ezetako (Zavala, Alegiak, 532)

c. Aita seme batzuk juan dira sabaira, aita katu aundijaz ta semia bere bai zerbaitakuan (JA.Moguel, Peru Abarka, 61)

Ildo berean, Azkuek ez du zelanbaista edo zelanbaita aldaerarik jasotzen, baina bai haietatik eratorriak ematen duten zelanbaistako eta zelanbaitako "cosa buena, apreciable, magnífica; chose bonne, appréciable, magnifique". Honako etsenpluan bezala (B-1):

(28) Zelanbaitako belarritako urrezkoak ekarri deutsaz osabeak Habanatik

Halaber zenbaitan (AN-Ond), bestela ere aurkitzen zail ez dena:

(29) Guk elkarrekin zenbaitan broma pixka bat ere izaten genuen (Lizaso, Jose Joakin Mitxelena gogoan, 42.orr.)

Eta beste horrenbeste nolabaitan ( $\mathrm{OEH}$, "de alguna manera") formarekin, nolabaitaren arrastorik aldean ez duena:

(30) Ustegabeko erasoa nolabaitan gaindu naiean (Tomás Agirre, Uztaro, 18..orr.)

\section{Gramatikalizazio prozesuaz}

\subsection{Izenordain zehaztugabeak: sailkapen bat eta inplikazio erlazioak}

Aspaldi xamar, Edmonson-ek (1983), polaritatedun adizki laguntzaileen hizkuntzarteko distribuzioa aztertu ondoren, hizkuntzek izenordain funtzioak eta izenordain formak nola uztartzen zituzten irudikatzen zuen diagrama bat proposatu zuen. Diagrama honetan, polaritatedun laguntzaileak agertzen diren kontestuak adierazten dira, halako moldez non izenordain bat funtzio horietako batean ager badaiteke, orduan ezkerreko funtzio guztietan ere agertu ahal izango baita: 
Haspelmath-ek (1997), 40 hizkuntzetako izenordain zehaztugabeak xehero aztertu ondoren, eta beste 100 hizkuntzetako datuak kontsideratu ondoren, dimentsio bitako diagrama baten bidez ordezkatzen du Edmonson-en dimentsio bakarreko diagrama ${ }^{24}$.

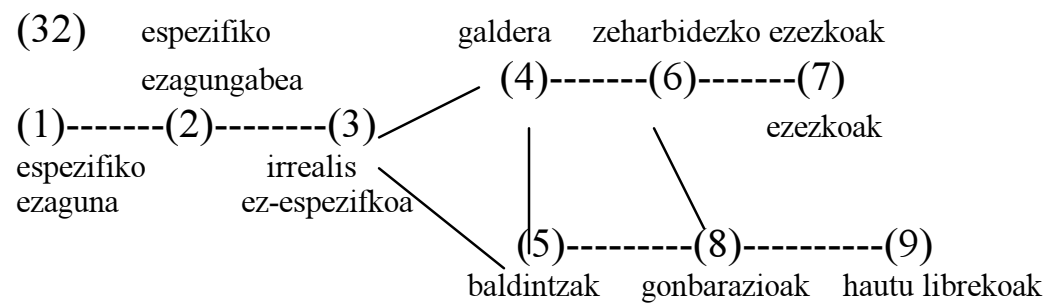

Haslpemath-en arabera, (32)ko mapak izenordain zehaztugabeen hizkuntzarteko distribuzioaren berri ematen digute. Batetik, (32)n adierazten diren kontestuak dira hizkuntza guztietan izenordain zehaztugabeak baimentzen dituztenak. Bestetik, eta hau da Haspelmath-en kontribuzio tipologiko handiena, izenordain jakin batek (forma jakin bateko izenordainak) funtzio bat baino gehiago betetzen badu, direlako funtzioak elkarren ondoan egon behar dute mapa horretan. Hizkuntzen arteko diferentziak forma eta funtzioaren uztarketari dagokionean, ez dira beraz zoriaren baitakoak, baizik eta hein handi batean mugatuak. Ez dago, esate baterako, Haspelmath-ek aztertu hizkuntzetan, kontestu ez-espezifikoetan eta zeharbidezko ezezkoetan agertzen den izenordain zehaztugaberik, galderazkoetan ere agertzen ez denik. Egon daiteke, hala ere, ezezkoetan eta zeharbidezko ezezkoetan agertzen den izenordain bat, galderazkoetan agertzen ez dena. Hizkuntzek modu batean edo bestean banatzen dute mapak adierazten duen funtzio eremua, baina banaketa lerroak ez dituzte sekula bereizten ondoz ondo edo marra batez lotuak diren kontestuak. Euskarak, gure egunean, honelako banaketa bide du (Haspelmath, 1997, 75.orr.):

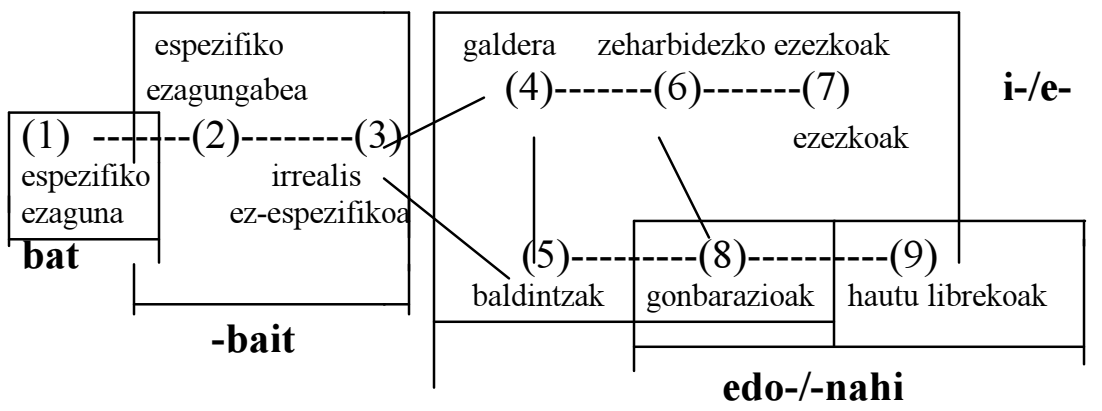

Haspelmath-ek proposaturiko mapak predikzio batzuk egiten ditu gramatikalizazio prozesuaren zer-nolakoaz ere: mapak erakusten dituzten ondokotasun erlazioak izenordain forma posible guztiak agortzen badituzte, gramatikalizazio bideak erlazio horiek ere obedituko ditu. Izenordainek aurreikus daitekeen modu batean eskuratuko dituzte funtzio berriak: hain zuzen ere ondoan (eta marra batez loturik) dauden funtzioetara lerratuaz. Haspelmath-en arabera horixe da gertatzen dena. Ikertzen dituen gramatikalizazio prozesuetan ez dago ezinezko ezein eremuri dagokion bitarteko formarik. Aldiz, gramatikalizazio prozesuaren emaitza desberdinak espero litekeen modukoak dira. Hautu libreko interpretazioa duten erlatibozko libreetarik eratorritako izenordainen kasuan honako taula ematen du adibide gisa (148.orr.): 


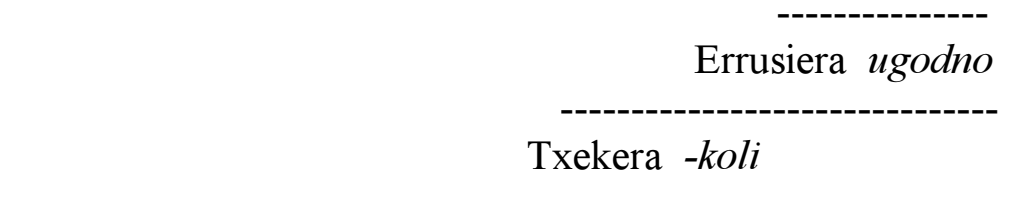

Frantsesa qui que ce soit

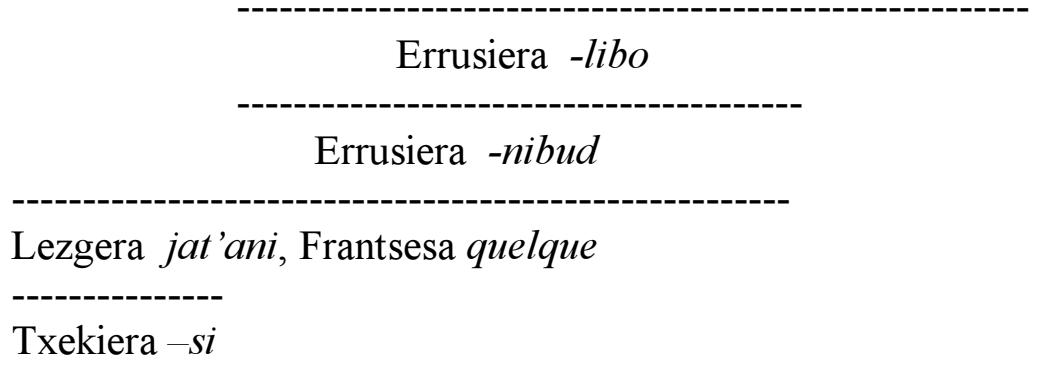

(34)ko taulak erakusten dituen gramatikalizazio bideek bi ezaugarri dituzte: (i) funtzio desberdinen ondokotasuna ez dela hausten (forma bakoitzak (32)-eko diagraman loturik agertzen diren funtzioak hartzen ditu); eta (ii) funtzioen etengabeko zabaltze bat baino areago, funtzio desberdinetarako lerratze bat dagoela, jatorrizko funtzioak atzean uzten dituena.

Euskararen kasuan, erlatibozko libreetarik eratorritako norbait/zerbait formak hautu libreko balioa izatetik kontestu ez-espezifikoak eta galdera/baldintzazkoak besarkatzen dituen eremuan baimenduak diren formak izateraino iritsi dira, balio existentziala dutenak. Honetan, euskarazko norbait/zerbait frantsesezko quelque-ren kide dira (lehenak izenordainak izanik, bigarrena determinatzailea bada ere). Frantsesezko quelque ere (Haspelmath, 1997, 139.orr.) erlatibo libre baten gramatikalizazioaren emaitza da. Hona frantses zaharreko kasu batzuk (Foulet, 1928, 190-191.orr.):

(34) Mes quel samblant qu'el en feist

li chevaliers samblant n'en fist (La Chastelaine de Bercy, 53-4)

XII.mendetik aurrera, quel (adjektibo balioarekin) eta que konplementatzailea elkarren ondoan agertzen hasten dira, guziz bat egin gabe, esapide ohiko batzuetan. Esapide horietan arruntena, a quel que paine "zein ere neke egiten baita, kosta ahala kosta". XII.mendean bertan, badira etsenplu bakan batzuk non quel...que hurrenkerak osagai bakarra osatzen duen:

(35) an quelque leu que vos ailliez "nora ere joaten baitzara, edonora zoazela ere" (Chrestien de Troyes, Li Contes del Graal, Perceval, 597-9)

Euskaraz bezala, frantsesezko quelque erlatibo libre batetik dator, eta hautu libreko izenordain zehaztugabe izatetik izenordain zehaztugabe existentziala izatera pasatu da.

Nola pasa dira baina, quelque eta norbait-en gisakoak existentzial izatera?

\subsection{Gramatikalizazioaren eragileez}


Lehen begiratuan, iduri luke izenordainaren bukaerako forma jokatuen ahulezia fonologikoa, eta haien ondorengo galerak - bait atzizkia sortu zutela. Behin hartaraz gero, hurrengo pausua bait-en aurretik zegoen flexio marka ororen (Kasu marka nahiz deklinabide atzizkien) kanporatzea izango zen. Kanporatze honen arrazoia morfologiaren antolaketa orokarraren baitan dago, eta honela eman daiteke (Haspelmath, 1993, 291.orr.; ikus baita ere Bybee, 1985, 40.orr.):

(36) Flexioa Deribazioaren Kanpoan Egon Beharraren Printzipioa

Morfologikoki konplexua den hitz bat hobetsia da flexio hizkiak deribazio hizkiak baino urrutiago baldin badira errotik edo hitz oinetik

Delako hobespen printzipioa $^{25}$, bestalde, ez da aspaldiko unibertsal ezagun baten birformulazioa baizik:

(37) Deribazioak eta flexioak biak ere erro edo hitz oinaren ondoan edo aitzinean badaude, deribazio hizkia beti dago erro edo hitz oinaren eta flexioaren artean (Greenberg, 1963: 28. Unibertsala)

Prozesu honen emaitza egungo formak dira. Bait-ek, atzizki bihurturik, flexio atzizki guziak kanporatu ditu izen oina jo arte, nor, zer, non eta noiz forma trinkoei lotuaz ${ }^{26}$.

Alabaina, bizkaierazko forma osoagoek erakusten dute (hain zuzen ere adizki jokatua gorde dutelako) segmentu fonologia ez dela aldaketaren eragilea izan. Kontutan hartu behar dugu baita ere, delako gramatikalizazio prozesuak ez duela ekarri ezabarazi duen egitura sintaktikoaren desagertzea. Norbait eta zerbait, biak nor (ere) baita eta zer (ere) baita egituretatik heldu zaizkigu (jatorrizko formak ezabatu dituen gramatikalizazio prozesu baten bidez), baina egitura horiek berak ez dira desagertu, produktibo izaten segitzen dute literatura klasikoan. Honek ez du hemen defendaturiko gramatikalizazio prozesua baliogabetzen. Forma gardenagoak eman duten bestelako gramatikalizazioetan, zernahi/nornahi kasuetan esaterako, antzeko gauza gertatzen da: nornahi eta zernahi-ren ondoan haien iturburua ematen duten nor nahi den, nor nahi baita ditugu, eta gramatikalizazio prozesuak hemen ere antzeko bitarteko formak eman ditu $(\mathrm{OEH}, \underline{\text { nornahi sarrera): }}$

a. Fite du garaitzen noren nahi konbata (Harizmendi,50)

b. Bazekien, nurk nahi bezin ongi (Larreguy, I 357)

c. Tranze batean nori nai gerta dakikeo argala izatea (Agirre Asteasukoa, Eracusaldiac III 295)

Ber gauza gertatzen da euskarazko norbait/zerbait-en antzeko bidea egin duen frantsesezko quelque-rekin. Lehen esan dugun bezala (3.2. atala), quelque forma balio kontzesiboko erlatibo libre batetik heldu da. XII.mendetik aurrera galdera izenordaina eta konplementatzailea elkarrekin lotuak agertzen hasten dira. XVII. menderako, bi elementuen lotura guziz burutua dago, eta quelque determinatzaile huts bezala erabiltzen da. Hori horrela delarik, XVII. mendeko idazleek quelque-ren azpian ustez dauden balio kontzesiboko erlatibo libreak enplegatzen segitzen dute, Molière-n perpaus honek erakusten duen bezala (Brunot eta Bruneau, 1949, 479.orr.):

Quelle violence que je me fasse (George Dandin,III, 7) 
Erlatibo libreetarik abiaturiko lerratzea inolako segmentu fonologikorik galdu ez duten forma osoagoen baitan gertatu da, eta jatorrizko forma uneoro "gogorarazi" behar zuten erlatibo libre kontzesiboen aitzinean. Hau da, izenordainen azpiko formak garden bihurtzen zituzten elementuak mantendu dira, baina ez dute gramatikalizazioa galarazi. Haspelmath-ek berak (1997, 136.orr.) ez du garbi ikusten nola gertatu den lerratze hori. Bistan da, hala ere, fonologikoki izenordainak forma ahulduak direla, segmentu fonologiaren aldetik ez bada, bai segmentuaz gainekoaren aldetik. Haspelmath-entzat, erlatiboen gramatikalizazioaren oinarrian batera gertatzen diren bi fenomeno daude: lehena, erlatibozko formen mailakatze balioaren galera da, berak "esanguraren ahultzea" deitzen duen prozesuaren bitartez azaltzen duena ${ }^{27}$. Adibide gisa, jarri ditzagun ondoz ondo izenordain zehaztugabe existentziala, eta ustez haren azpian dagoen erlatibo librea:
a. Norbait ekar dezakezu
b. Nor ere baita ekar dezakezu

Hautu libreko erlatiboak eskala pragmatiko baten azken maila adierazten du. Norbait existentzialak, berriz, ez. Biek partekatzen dute ez-espezifikotasuna. Hautu libreko erlatibo bat balio existentzialeko izenordain bilakatzen denean, esan daiteke gramatikalizazioa semantikoki mailakatze funtzioaren (foko tasunaren) galerari zor zaiola, eta fonologikoki (hona hemen bigarren fenomenoa) fokoak berez eskatzen duen azentuaren galerari. Galeraren ondoan, mailakatzeak suposatzen zuen multzo jakin baten gaineko zenbaketa ahalmena galtzen da. Gelditzen den zenbaketa ahalmena existentzial huts batena da. Hau jakina, gramatikalizazio prozesuaren parte bat besterik ez da. Ez dakigu, esate baterako, nola integratu ziren forma hauek perpaus egituran argumentu xoil gisa, jatorrian adjunktuak zirelariak. Atal honek bistan da, ikerketa luzeagoa behar du.

\subsection{Zer zegoen zerbait izan baino lehen}

Hemen aurkeztu dugun gramatikalizazio prozesuak berehalako galdera pizten du: norbait/zerbait bezalako izenordainak euskarak aspaldi gabe bildutako gaiak badira, zerk betetzen zuen izenordain horiek egun betetzen duten espazioa? Leizarragarengana jotzen badugu, norbait/zerbait-en ondoan edozein(bat) ere aurkitzen dugu balio esistentzialarekin baiezko perpausetan ${ }^{28}$. Izenordain zehaztugabeen sistemaren bilakaerak azterketa serios bat behar duen alorra da, artikulu honen mugak guziz gainditzen dituena. Litekeena da, hala ere, balio esistentziala ere bazuen edozein(bat)-ek egungo norbait/zerbait-en funtzioak betetzea. Hemen besterik gabe, edozein(bat) existentzial balioko etsenplu batzuk emango ditut, OEHtik hartuak.

(41) a. Baina are erranen du edozeinek..."Quelqu'un dira" (Leiç. Iac, 18)

b. Baina baldin edozeinek uste badu ezen desohore duela "Si quelqu'un..." (Leiç. Cor 7,36)

c. Zen bada fariseutaric edozeinbat Nikodemo deitzen zenik (Leiç. Io 3,1)

d. Fikotze bat zuen edozein batec landatua bere mahastian (Leiç. Lc 13,6)

\section{Bibliografia}




\section{Korpusa \\ 1.1. Hiztegiak}

Azkue, R.M. 1905. Diccionario Vasco-Español-Francés, Bilbao.

Euskal Herriko Hizkuntz Atlasa. Ohiko euskal mintzamoldeen antologia. Bilbo:Euskaltzaindia. 1999.

Diccionario Retana de Autoridades de la Lengua Vasca. Bilbo:La Gran Enciclopedia Vasca. 1976-1991.

Lhande, P. 1926. Dictionnaire Basque-Français, Paris: Beauchesne.

Michelena. L. 1987-1999. Diccionario General Vasco-Orotariko Euskal Hiztegia. Bilbao: Euskaltzaindia.

\subsection{Idazlanak.}

Agirre, T. 1950. Uztaro $^{2}$, Bilbo.

Aguirre, J.B. 1850. Eracusaldiac III, Tolosa.

Aguirre, D. 1912. Garoa. Durango.

Axular, P. 1643. Gero. Facsimil edizioa. Bilbo:Euskaltzaindia, 1988.

Añibarro, P.A. 1821. Escu-Liburua'2. Tolosa, 1821.

Astarloa, P. 1818. Urteco Domeca gustijetaraco verbaldi icasbidecuac II, Bilbo.

Beovide, C. 1885. Asisko Loria, Tolosa.

Dechepare, B. 1545. Linguae Vasconum Primitiae. Patxi Altunaren edizio kritikoa, Bilbao: Mensajero, 1987.

De la Quadra. 1784. Doctrina Christinaubarena. Eskz. In Gidor Bilbao. 1998. "De la Quadra-k Bermeon 1784an idatzitako eskuizkribuak. I. Doctrina christinauarena" ASJU XXXI-1, 247-336.

Iztueta, J.I. 1847. Guipuzcoaco provinciaren condaira edo historia, Donostia.

Leizarraga, J. 1571. Iesus Christ Gure Iaunaren Testamentu Berria [...]. La Rochelle. T. Linchsmann eta H. Schuhardt faksimilean argitaratua, I. Leiçarragas Baskische Bücher von 1571 [...], Strasbourg:Trübner. Honen faksimila, Bilbao: Euskaltzaindia, 1990, 241-1197.

Lizaso, K. 1998. Jose Joakin Mitxelena gogoan. Auspoa liburutegia, 256. Gipuzkoa: Sendoa 
Mitxelena, K., A. Tovar eta E. Otte. 1981. "Nuevo y más extenso texto arcaico vasco: de una carta del primer obispo de México, Fray Juan de Zumárraga" Euskera XXVI (2. Aldia), 5-14.

Moguel, J.A. 1802 ingurukoa. Peru Abarka, Durango, 1881.

Moguel, J.J. 1885. Mayatz-illeraco berba-aldijac, Tolosa.

Moguel, V. 1804. Ipui Onac. Donostia.

Olaechea, B. 1763. Doctrina cristiana. Gasteiz.

Refranes y Sentencias. 1596. J. Lakarraren edizio kritikoa, Bilbao: Euskaltzaindia, 1998.

Sarasola, I. 1983. "Contribución al estudio y edición de textos antiguos vascos," ASJU XVII, 69-212.

Uriarte, J.A. 1850. Marijaren illa edo Maijatzeco illa, Bilbo.

Urquizu, D.L. 1737. Liburu Virgina Santissimien errosario santuena. Iruñea.

Zavala, J. M. 1820 inguruan. Fábulas en dialecto vizcaíno. RIEV 1907, 87-98, 529543; 1909, 27-40.

Zuzaeta, M.I. (XIX.mende hasiera). F. Ondarra eta A. Unzueta (arg.) Idazlanak, Bilbao.

\section{Erreferentziak}

Azkue, R.M. [1923-1925]. Morfología Vasca I, II, III. Bilbo:La Gran Enciclopedia Vasca. 1969.

Bhat, D.N.S. 2000. "The indefinite-interrogative puzzle" Linguistic Typology 4, 365400 .

Brunot, F. 1929. Petite syntaxe de l'ancien français. Librairie Honoré Champion-ek berrargitaratua, Paris, 1990.

Brunot, F. eta C. Bruneau. 1949. Précis de grammaire historique de la langue française. Paris:Masson et Cie.

Cheng, L. 1991. On the typology of wh-questions. MITko tesi argitaragabea.

Culicover, P. eta R. Jackendoff. 1997. "Semantic Subordination Despite Syntactic Coordination" Linguistic Inquiry 28.2, 195-217.

De Rijk, R. 1981. "Euskal morfologiaren zenbait gorabehera" De linguae Vasconum:Selected Writings, Supplements of the Anuario del Seminario de Filología Vasca Julio de Urquijo XLIII, Bilbao: EHU. 
Etxepare, R. 2001. "Nori berea: nor bere egiturak euskaraz" Euskaltzaindiaren XV. Nazioarteko Biltzarraren agirietan agertzekoa.

Euskaltzaindia.1985.Euskal Gramatika. Lehen Urratsak-I. Iruñea.

Euskaltzaindia. 1993. Euskal Gramatika Laburra:Perpaus Bakuna. Bilbo.

Fauconnier, G. 1985. Mental Spaces. Cambridge, Massachusetts:MIT Press.

Greenberg, J. 1963. "Some universals of grammar with particular reference to the order of meaningful elements" In Greenberg (arg.) Universals of language. Cambridge, Massachusetts:MIT Press. 73-113.

Haspelmath, M. 1993. "The diachronic externalization of inflection" Linguistics 31, 279-309.

Haspelmath, M. 1997. Indefinite Pronouns. Oxford Studies in Typology and Linguistic Theory. Oxford: Clarendon Press.

Haspelmath, M. eta E. König . 1998. "Concessive conditionals in the languages of Europe". In Johann Van der Auwera (arg.) Adverbial Constructions in the Languages of Europe. Empirical Approaches to Language Typology, Eurotyp 20-3. Mouton de Gruyter.

Lafon, R. 1944. Le système du verbe basque au XVI siècle. Ėditions Delmas, Publications de l'université de Bordeaux. Elkar argitaletxeak birrargitaratua, 1980.

Lafon, R. 1966. "La particule bait en basque: ses emploies morphologiques et syntactiques" Ikus J. Haritschelhar eta P. Charritton (arg.) Vasconiana. Bilbo:Euskaltzaindia, 1999, 667-687.

Lafon, R. 1973. "La langue basque" Ibidem, 57-120.

Li, Y-H.A. 1992. "Indefinite Wh in Mandarin Chinese" Journal of East Asian Linguistics 1, 2.zbka. 125-156.

Mitxelena, K. 1965. "Vasco-románica" Revista de Filología Española, 48, 105-119. Lengua e Historia artikulu bilduman berrargitaratua, Madrid:Paraninfo, 1985, 268281.

Mitxelena, K. 1985. Fonética Histórica Vasca ${ }^{3}$. Publicaciones del seminario Julio de Urquijo, Donostia: Gipuzkoako Foru Aldundia.

Oyharçabal, Bernard. 1987. Étude descriptive de constructions complexes en basque: propositions relatives, temporelles, conditionnelles et concessives. Thèse de doctorat d'état, Paris.

Ortiz de Urbina, J. 1986. "Aspects of Basque lexical phonology" Fontes Linguae Vasconum 48, 205-224. 
Rebuschi, G. 2000. "À propos d'une construction non-standard du basque" Lapurdum V, 223-237.

Rebuschi, G. 2001. "Sur la forme syntaxique et la forme logique de quelques phrases complexes" Argitaragabea.

Trask, R.L. 1997. The History of Basque. Routledge.

${ }^{11}$ Eskerrak eman nahi dizkiet artikulu honen idazketan lagundu didatenei: Joseba Lakarra, Bernat Oihartzabal, Georges Rebuschi eta Xarles Videgaini. Haietariko inor ere ez da, jakina, hemen esaten denaren erantzule.

${ }^{2}$ Nor/zer bezalakoak euskaraz ez dira segurenik berez galderazkoak. Nor/zer formek indar zenbatzaile aldakorra dute, batzutan unibertsal gisa (a), bestetan galdera izenordain gisa (b) eta bestetan berriz izenordain anaforiko plural gisa jokatzen dutelarik (c):

(i) a. Nork bere herria maite du

b. Nork maite du bere herria?

c. Nor oinez nor autobusez etorri zen/ziren

Etxepare-k (2001, agertzekoa) nor/zer elementuen zenbatasun ahalmena sintaktikoki mugarritua dela proposatzen du, hau da, nor/zer-en zenbaketa ahalmen askotarikoak perpaus egituran gauzatuak diren tasun kuantifikazional diferenteekin asoziatuak izatearen ondorio direla, Beghelli (1995), Beghelli \& Stowell (1997) eta Szabolcsiren (1997) lanen izpirituan. Aurrerakoan nor/zer formak, ohi bezala, galderazkoak direla emango dut, irakurketa errazte aldera.

${ }^{3}$ Existentzialen sailean sartu behar dira baita ere nor edo nor, nor edo hura edo nonor-en gisakoak. Badirudi, testuaren lekukotasunari begiratzen badiogu behintzat (OEH-ek ematen duena) forma hauek besteak baino berriagoak direla. Zaharragoak diren izenordainen jatorriaz jarduten garen bitartean bazter utzi daitezke beraz.

${ }^{4} \mathrm{Bi}$ exenpluok George Rebuschi-k helaraziak dira.

${ }_{6}^{5}$ Erreferentzia guztiak Orotariko Euskal Hiztegitik hartuak dira, besterik esaten ez bada.

${ }^{6}$ Sarasolak bere iruzkinetan hauxe dio: "la - $a$ de cerbayta, clarísima en el manuscrito, no acertamos a explicarla si no es por lapsus de escritura" Mitxelenak, Tovar-ek eta Otte-k (1981) berriz, "çerbayta, con una - $a$ inexplicable" diote. Artikulu honetan defendatzen den hipotesiaren arabera, ez da miresteko forma bat, baizik eta Azkuek jasotako zepaita-ren kidea.

${ }^{7}$ OEHak ere norabaita bat ematen du, Salbatore Mitxelenarengandik jasoa. Hala ere, zaila da jakitea hemen norabait eman duen forma osoago bat dugun ala nonbaiten gisako forma bat, zeinetan bukaerako $-a$ hori izenordainaren barneko adlatiboa errepikatzen duen. Norabaitera bezalako forma pleonastikoak ez dira bestela ere ezagungabeak:

(i) Jolasak norabaitera eraman ezbaditu (Agirre, Garoa, 162.orr.)

${ }^{8}$ Lhande-k honen jatorria garbi zuen (1926): nunebeita $<$ non ere beita. Berez, laburtu gabeko formak ere aurkitzen ahal dira. Euskal Herriko Atlasaren Antologiak non ere beita dakar, "seguru aski" esanahiarekin, Urdiñarbeko (Zuberoa) hiztun bati hartua: ...hori entzüna düzu nun ere beita...(169. orr.). Ikus 3.atala.

${ }^{9}$ Hitzez hitz: "Es caso muy curioso y digno de notarse que bait cuando, en vez de prefijo conjuntivo [adizkiari lotzen zaiona]... es sufijo graduativo [izenordainei lotzen zaiena], tiene las mismas variantes baist (B) y beit (S)". Euskal Herriko Atlasak Azkuek jaso gabe utzi zituen antzeko aldaerak jasotzen ditu Zuberoan: nuispaist (Sohüta, Altzai eta Altzürükün) eta nuspatx (Santa Garazin). Eskerrak Xarles Videgaini datuengatik. Diccionario de Autoridades-ek eta OEHak nuizpaizt jasotzen dute. Ikus 16. oharra.

${ }^{10}$ Aipamena Vasconiana izenburupean agertutako artikulu bildumatik egiten dut: "le suffixe -bait est certainement apparenté à $b a$, bai 'oui'. L'adjonction de bait à un interrogatif indéfini soulignait sa valeur affirmative et lui ôtait tout caractère interrogatif." (683.orr.). Gavel-ek ere antzeko intuizioa izan omen zuen, garbiki azaldu ez bazuen ere (688.orr,).

11 "Les deux sintagmes norbait dago 'quelqu'un demeure' et nor baitago 'celui qui demeure' sont deux formes différenciées d'un type plus ancien où bait pouvait indifférement, avec valeur affirmative dans les deux cas, s'ajouter au pronom ou au verbe. Dès l'époque des plus anciens textes, bait est soudé soit à l'un soit à l'autre. Mais il reste quelques traces du temps où bait était une particule indépendente. 
Ainsi, l'ergatif de norbait,...est chez dechepare nork bait ere, oú c'est nor qui porte la marque du cas..." (688.orr.)

12 "The indefinites like norbait 'somebody' have an obvious origin. Originally, it seems, the interrogatives were also used as indefinites, and were marked in this function by the presence of the prefix bait- on the finite verb. But sequences like *nor baitzen 'it was somebody' were reanalysed as norbait zen, with the affix being transferred from the verb to the pronoun." (1997, 197-198.orr.)

${ }^{13}$ Hau Haspelmath-en hautua da. Ez da errez ikuspegi hertsi honen bitartez euskarazko edo-nz izenordain zehaztugabeen gisako formen berri ematea. Haspelmath bera ere ohartzen da (1997, 164166.orr.), baina aldi berean kausitzen du berak azterturiko hizkuntza gehienetan disjunkzioa nahi izan bezalako aditz batetik eratorria nahiz balio eskalarra duen partikula batetik eratorria dela (komunzki, euskarazko "behintzat"-en ordaina dena). Galderazkoen forma duten izenordain zehaztugabeei buruz (e.g. Txineraren kasua, Li (1992)), berriz, galdera hitzen aldean izenordainek izaera konplexua dutela defendatzen du, horretarako zero-deribazioa behar badu ere. Klima-ren (1966) analisian ez bezala, beraz, Haspelmath-entzat izenordainak galderazko formetarik eratorriak dira. Izaera konplexukoak ez diren izenordain zehaztugabe bakarrak berak generikoak deitzen dituenak dira (182.orr.), "pertsona", "gauza", "lekua" edo "denbora" bezalako kontzeptuak adierazten dituzten izen soilak zenbait hizkuntzatan izenordain zehaztugabe gisa baliatzen ahal direnak (frantsesezko rien bezalakoak). Agian hemen sartu beharko genuke euskarazko deus ere (<lat. genus, cf. Mitxelena, 1965). Haspelmath-en ustea, galderazkoen eta forma bereko izenordainen arteko erlazioari dagokionean ez zait aski oinarritua iruditzen, eta izenordainen iturburu posibleez ari garenean kontutan hartzeko zerbait da. Ez dut uste hala ere lan honen gaia, bere zehatzean, ukitzen duenik.

${ }^{14}$ Hona hemen bigarren tipoaren exenplu gehiago. (Haspelmath, 1997, 138. orr.)

$\begin{array}{lll}\text { Alemaniera } & \text { wer auch immer }=\text { edonor } & \text { wer "nor", auch "ere" } \\ \text { Serbo-kroaziera } & \text { i-ko =edonor } & \text {-ko "nor", i- "ere" } \\ \text { Indonesioa } & \text { siapa-pun=edonor } & \text { siapa- "nor", -pun "ere" } \\ \text { Gooniyandia } & \text { ngoorndoo-ngaddaya=norbait } & \text {-ngaddaya "ere" } \\ \text { Sanskritoa } & \text { kas cana }=\text { edonor } & \text { cana "ere" } \\ \text { Japoniera } & \text { nani-mo=ezer ez } & \text {-mo "baitaere" } \\ & \text { nan-demo=ezer/deus } & \text {-demo "ere" } \\ \text { Hindi/Urdu } & \text { koii bhii }=\text { inor } & \text { koii "nor (zehaztugabea)" } \\ & & \text { bhii "ere" }\end{array}$

${ }^{15}$ Inork esan lezake baita-k baduela eiterik aski baita lokailuarekin, eta hau ez dagoela urrutiegi mailakatze funtzioa duen ere-tik. Antzekotasunaren azpian mamizko deus ere ez dagoela garbi aski uzten dute honako hiru datuek: (i) baita aditzondoak ez du baista edo beita aldaerarik; (ii) baita-k ez du sekulan, guk dakigunez, mailakatze funtziorik izan, bere baitarik; eta (iii) baita eta ere elkarrekin agertzen direnean ordena baita... ere da, ez ere... baita, baina azken hau da nolerebait izenordain konplexuetan aurkitzen duguna.

${ }^{16}$ Jakina, honek behartzen gaitu - baist aldaeraz galde egitera. Konbikzio haundirik gabe mintzatuaz, baist -en azpian bai ez eta egon liteke (cf. baizik<*bai-ez-ik eta baizen >*bai-ez-en, Lafon, 1957-58, 242-tik aurrera).

${ }^{17}$ Nor -en kasuan behintzat, ere-rik gabekoak ere badira (OEH):

(i) Nor baita txarrena,/ hark dik hark hobena (Zalduby, RIEV 1909, 228)

${ }_{18}$ Baita Pouvreau ere, bere hiztegian: Nor ere baita "quel qu'il soit". Eta Urte, gramatikan: Norerebaita,... "Qui que ce soit..." (Gramatika, 75)

19 Bide horretatik abiatuak iduri dute iparraldeko nik dakita nor/zer/non/zenbat bezalakoak, - $a$ galderazkoarekin. Eskerrak B. Oihartzabali oharragatik.

${ }_{20}$ Azkuek zeinein (BN-aezk) jasotzen du hiztegian "cualquiera; quelconque", zein+nahi+den -etik, bere ustetan.

${ }^{21}$ Hemen kontutan hartu behar da ere euskaraz juntagailuak klitizatzen direnean atzetik egiten dutela, cf. edo-ren joera juntadura moztuetan (bihar-edo joango da) eta -ta atzizkia orohar. Eskerrak B. Oihartzabali ohar honengatik.

${ }^{22}$ Trask-en ustetan edonor nor edo nor formatik heldu da, laburbidez. Hipotesiak gutxienez problema bat du, eta da nor edo nor eta edonor formek ez dutela zenbatasun balio bera (baina ikus 4.3.atala).

${ }_{23}$ Esan behar da testuan ematen ditudanak ez direla egitura libreak, korrelatiboak baizik. Asumituko dut forma libreak ere izan zirela edo badirela, hiztegiek aipatzen ez badute ere.

${ }^{24}$ Termino batzuk ez dira beharbada identifikatzen errez: "zeharbidezko ezeztapena"-z (Haspelmath-en "indirect negation") adierazi nahi dugu ezeztapena eta harekin loturiko izenordaina perpaus berean agertzen ez diren kasua, hainbat hizkuntzatan izenordain berezi bat behar duena. Adibide gisa, hungariera (Haspelmath, 1997, 33): 
(i)

a. Nem lát-t-am sem-mi-t

ez nekusan ezer b. Nem hisz-em, hogy vala-ki lát-t-a volna ez dut-uste Konp inork ikusi duen

Non ezeztapena dagoen perpaus berean agertzen den izenordain zehaztugabea eta ezezko formarik ez duen menpeko perpaus batean agertzen dena bi izenordain sail diferenteri dagozkion, formalki.

"Irrealis ez-espezifikoa" terminoaz, berriz, subjektu baten menpeko espazio mental edo denbora-moduzko batetik kanpo erreferentziarik ez duen izenordaina (Fauconnier, 1985), hizkuntza askotan ere forma berezia galdetzen duena. Haspelmath-en kontestu guztiak lau bitariko tasunen laguntzaz karakteriza daitezke (1997, 119.orr.):

(ii) Hiztunaren ezaguna vs. hiztunaren ezagungabea

(iii) Espezifikoa vs. ez-espezifikoa

(iv) Mailakatzerik erakusten duena vs. mailakatzerik erakusten ez duena

(v) Ezeztapenaren menpekoa vs. ezeztapenaren gainekoa

Mapako loturak halako moldez daude eratuak non tasun bera duten funtzioak maparen eremu jarraitu bat osatzen baitute.

${ }^{25}$ Haspelmathen arrazoia, (24) antolaketa printzipio hertsia baino hobespen printzipio gisa hartzeko, gramatikalizazio prozesuan sortzen diren forma pleonastikoak dira. Kontsideratu esate baterako Georgieraren izenordain zehaztugabeen (edonor/zer sailari dagozkionak) bilakaera historikoa:

\begin{tabular}{|c|c|c|}
\hline nom & $\begin{array}{l}\text { forma zaharra } \\
\text { ra-me }\end{array}$ & bitartekoa \\
\hline dat. & ra-s-me & ra-s-me-s \\
\hline dv. & ra-d-me & ra-d-me-d \\
\hline gen & r-is-me & \\
\hline instr & r-iti-me & \\
\hline
\end{tabular}

Non $r a$ - gure zer -en ordaina den eta - me izenrodain zehaztugabea sortzen duen partikula. Forma zaharretan, euskaraz bezala, partikula hori kasu marken ondoren dator $(-s-,-d-$, -is- eta -iti- kasu markak dira). Bitarteko formak pleonastikoak dira, kasu marka me-ren aurretik eta ondoan agertzen direlarik. Forma berriek flexioa kanpoan dute. Haspelmath-en arabera, lexikoaren antolaketa morfologiko hertsi batek ez du forma pleonastikoen presentzia esplikatzen. Euskaraz forma pleonastikoak ere agertzen dira, flexioaren kanporatze prozesuan: nondikbaitik, norabaita, nonbaiten. Halere ohar gaitezen ez dugula *norkbaitek, *noribaiti edo *nortzubaitzu bezalakorik. Agian ez da kasualitatea, georgieraren kasuan ere genitibo eta instrumentaleko formak aldaera pleonastikorik ez sortzea gramatikalizazio prozesuan zehar. Litekeena da forma pleonastikoen presentziak maila deribazional eta flexiboaren arteko bereizketa ez kolokan jartzea, baizik eta maila flexiboan bertan dauden linearizazio arauen laxatzea erakustea.

26 Interesgarria da, hartara, egungo norabait/nonbaitera alternantzia, adlatiboaren azpian lokatiboa dagoela erakusten duena. Hau bestalde ere ikusten da zubererazko deklinabidean, inesiboko $-a$ morfema posposizionala ager baitaiteke adlatiboan: oihaniala, etxilat $>$ etxialat (B. Oihartzabali zor diodan oharra).

${ }^{27}$ Honek primitibo baten balioa du Haspelmathentzat, ez baita beste inondik ere segitzen. Ez da, bistan da, deuseren esplikazio bat (nahiz eta gramatikalizazioaren ikerlariek honelakoak esplikazio gisa hartzen dituzten). Ez nator bat printzipio hauen alegiazko balio esplikatiboarekin. Aldiz, fenomenoa orokorra den neurrian, eta modu intuitiboan honela deskriba daitekeen neurrian, esplikazio baten esperoan dagoen jeneralizazio gisa hartuko dut.

28 RS-en aldiz, edozein "cada uno/chacun"-en adierarekin agertzen da. OEHak inor/nehor polaritatedunak ekartzen ere ditu balio existentzialdun gisa. Etsenplu bereziki garbia da Pouvreau-ren hau:

(i) Nola nork ere nihor maite baitu naturalezako amorioz (SP Phil 128)

Hala ere ez dirudi nehor/inor izenordainak edozein existentzial klase direnik: Haspelmath-en "irrealis non-specific" kategoriari dagozkiola ematen du. Kategoria hau gauzatzen duten formak distribuzio kontestuetan ere agertzen dira, banaketa gai bihurtzen direlarik (Pouvreau-ren exenpluan bezala). Gainerakoan, ekialdeko XVI eta XVII. mendeko testuetan, polaritatezko kontestuetarik kanpo nihor-ek interpretazio inpertsonala behartzen duela ematen du:

(ii) a. Eta hec ethorri ciradenean Iesusgana, othoitz ceguioten affectionatuqui, cioitela, ecen digne cela nehorc hura aithor lieçon (Leiç. Luc 7, 4)

b. Ceren bertceac bertce direla (lehen erran den beçala) gazteco usantçac iarraiquitcen ohi çaitça nehori, çahartcean ere. (Ax. 175. orr.)

c. Nehorc debecu den gauça ... desiratzenago du (Ax. 359) 